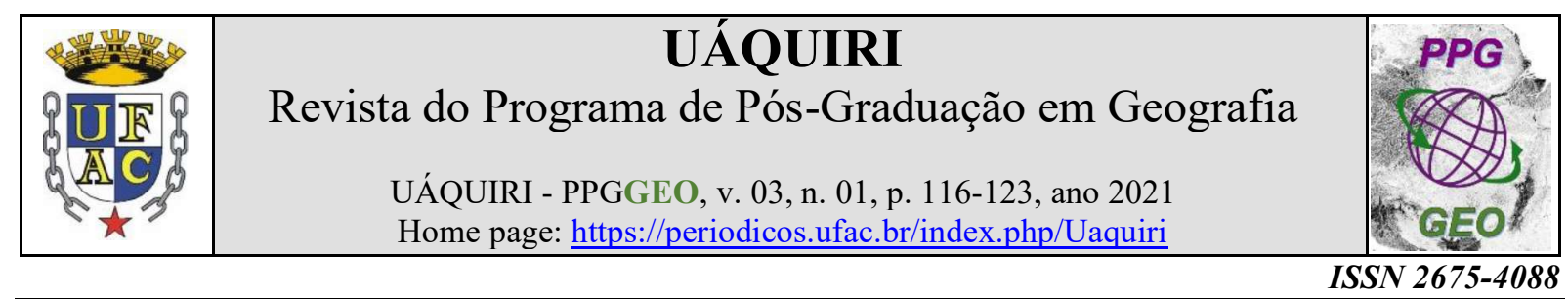

\title{
(RELATOS DE EXPERIENCIAS) \\ VAMOS FALAR SOBRE NOSSA CIDADE? UMA PROPOSTA DE SD PARA O ENSINO REMOTO COM AS NOVAS TECNOLOGIAS
}

\author{
Ana Luiza Luzio da Silva* \\ ORCID: https://orcid.org/0000-0003-0504-2624 \\ Mestranda em Educação no PPGE na instituição Unesp-Marília *alluzio@gmail.com \\ Aprovado como destaque no I Simpósio Nacional de Metodologias Ativas na Educação Profissional e Tecnológica (I SinmaEPT). \\ Publicado em: 30/07/2021 \\ DOI: https://doi.org/10.47418/uaquiri.vol3.n1.2021.5134

\begin{abstract}
Neste trabalho tratamos do ensino de língua inglesa dentro do contexto do Ensino Fundamental I, também conhecido como anos iniciais. Apresentamos uma proposta de Sequência Didática adaptada para a modalidade de ensino remoto, que é o que se encontra vigente atualmente. Para isso, percorremos o seguinte trajeto, mostraremos de que forma a língua inglesa está em processo de inserção nos anos iniciais e quais são as concepções teóricas que se encontram por trás desse processo. A partir desses elementos, delineamos algumas considerações, como por exemplo, as vantagens encontradas nessa modalidade, e quais foram as dificuldades enfrentadas.
\end{abstract} \\ RESUMO
}

Palavras-chave: Educação; Ensino de língua inglesa; Metodologias ativas.

\section{LET'S TALK ABOUT OUR CITY? A DS PROPOSAL FOR REMOTE EDUCATION WITH NEW TECHNOLOGIES}

\section{ABSTRACT}

In this work we deal with English language teaching within the context of Elementary School I, also known as early years. We present a proposal for a Didactic Sequence adapted to the modality of remote teaching, which is currently in force. In order to do this, we will go through the following path, we will show how the English language is in the process of being inserted in the early years and what are the theoretical conceptions that lie behind this process. Based on these elements, we outline some considerations, such as the advantages found in this modality, and what were the difficulties faced.

Keywords: Education; English language teaching; Active methodologies.

\section{¿HABLEMOS DE NUESTRA CIUDAD? UNA PROPUESTA SD PARA LA EDUCACIÓN A DISTANCIA CON NUEVAS TECNOLOGÍAS}

\section{RESUMEN}

En este trabajo nos ocupamos de la enseñanza del idioma inglés en el contexto de la Escuela Primaria I, también conocida como años iniciales. Presentamos una propuesta de Secuencia Didáctica adaptada a la modalidad de enseñanza a distancia, actualmente vigente. Para ello, pasaremos por el siguiente camino, mostraremos cómo está en proceso de inserción la lengua inglesa en los primeros años y cuáles 
son las concepciones teóricas que se esconden detrás de este proceso. Con base en estos elementos, delineamos algunas consideraciones, como las ventajas encontradas en esta modalidad, y cuáles fueron las dificultades enfrentadas.

Palabras clave: Educación; Enseñanza de lengua inglesa; Metodologías activas.

\section{INTRODUÇÃO}

Com o advento do Covid-19, as instituições escolares optaram pelo lockdown, fechamento de seus espaços físicos enquanto medida profilática para contenção do vírus. No estado de São Paulo, essas medidas passaram a vigorar a partir do mês de março e ainda perduram na maioria das regiões. Dessa forma, a alternativa encontrada pelos sistemas de ensino, de esfera municipal, estadual e federal foi a adoção do ensino remoto. É importante salientar que nas instituições universitárias, essa modalidade já se encontra mais fortalecida, com a existência de ambientes virtuais próprios e personalizados para atender as demandas educacionais. No entanto, para os níveis de ensino de Educação Infantil e Fundamental, essa mudança foi inovadora.

Neste sentido, foi necessária uma reorganização no planejamento escolar desses níveis de ensino que será abordada a seguir. Este artigo está inserido dentro de uma realidade de um município no interior de São Paulo no nível de Ensino Fundamental-I, que conta com Língua Inglesa como componente curricular.

Este artigo trata do nível de ensino do Ensino fundamental I (anos iniciais), que compreendem desde o $1^{\circ}$ até o $5^{\circ}$ ano. Esse ciclo pertence (no âmbito público), geralmente a esfera municipal. O objeto de estudo será o ensino de língua inglesa dentro desse ciclo, o que ainda se caracteriza como experiências isoladas, considerando que não existem legislações específicas que garantam a presença desse componente a partir dos anos iniciais.

Na Lei de Diretrizes e Bases (LDB) a garantia do ensino de língua estrangeira é contemplada apenas a partir do sexto ano, ou seja, no início do Ensino Fundamental-II (anos finais). Assim, a oferta de uma língua estrangeira no EF-I é de caráter optativo, e tem caracterizado como uma estratégia de alguns sistemas municipais. De acordo com Rocha (2010) no ensino privado essas iniciativas são mais recorrentes, inclusive com a alta incidência de escolas bilíngues.

Ainda de acordo com as legislações sobre o tema o Parâmetro Curricular Nacional de Língua Inglesa de 1998, versa sobre de que maneira deve ocorrer o ensino e quais são os objetivos a serem atendidos:

[...] a aprendizagem de uma língua estrangeira deve garantir ao aluno seu engajamento discursivo, ou seja, a capacidade de se envolver e envolver outros no discurso. Isso pode ser viabilizado em sala de aula por meio de atividades 
pedagógicas centradas na constituição do aluno como ser discursivo, ou seja, sua construção com sujeito do discurso via língua estrangeira. Essa construção passa pelo envolvimento do aluno com os processos sociais de criar significados, por intermédio da utilização de uma língua estrangeira. (BRASIL, 1998, p. 19)

É importante esclarecer que a área de ensino de língua inglesa para crianças (LIC) tem se destacado nos últimos anos nos debates acadêmicos. Apesar de ainda carecer de políticas públicas direcionadas para o ensino na primeira infância, as iniciativas vêm se fortalecendo. No meio acadêmico, os estudos direcionados para essa área tem se destacado com produções relevantes sobre a temática. Nesse sentido, cada vez mais, se justifica discutir a respeito da importância de LIC.

Considerando o contexto do LIC, neste trabalho a intenção é descrever as mudanças proporcionadas pela adoção do ensino remoto, em específico no componente curricular de Língua Inglesa, e apresentar uma Sequência Didática adaptada para essa nova modalidade contemplando o uso de novas tecnologias.

\section{DESENVOLVIMENTO}

Análise qualitativa de uma Sequência Didática elaborada para aulas no ensino remoto de Língua Inglesa no Ensino Fundamental cujo conteúdo temático é a cidade e seus espaços. Dessa forma, serão descritas de forma detalhada como essa sequência foi organizada para atender aos propósitos da nova organização didático-pedagógica.

\subsection{Fundamentação teórica}

A concepção de língua/linguagem que orienta é a mesma defendida por Rocha (2010, p. 10) que defende que o pesquisador deve partir:

[...] da premissa de que aprendizagem do inglês no EFI público deva orientarse por visões de língua/linguagem que priorizem o caráter sócio historicamente marcado das relações humanas, a fim de que possam efetivamente criar oportunidades de circulação de uma pluralidade de discursos nesse processo e, assim, viabilizar a construção de conhecimentos e capacidades que permitam à criança agir mais ativamente em seu meio através da língua inglesa.

Como referencial teórico-metodológico a opção foi pelos estudos bakhtnianos, assim como fez Rocha (2010) for considerar que o ensino de uma língua estrangeira é a circulação do sujeito por uma amplitude de discursos. De acordo com o Círculo de Bakhtin, não é possível viver em uma sociedade sem considerar o que há por trás do discurso, que se faz através de 
signos. Pensar em uma aula de Língua Inglesa, deve, portanto, levar em consideração que existe um movimento de transculturalidade representado pelos signos que é explicitada abaixo:

\begin{abstract}
Os signos também são objetos únicos e materiais e [...] qualquer objeto da natureza, da tecnologia ou de consumo pode se tornar signo. Neste caso, porém, ele irá adquirir uma significação que ultrapassa os limites da sua existência particular. O signo não é somente parte da realidade, mas reflete e refrata uma outra realidade, sendo por isso mesmo capaz de distorcê-la, ser-lhe fiel, percebê-la de um ponto de vista específico e assim por diante. (VOLÓCHINOV, 2017, p.93)
\end{abstract}

A partir do fechamento das escolas, todas as aulas foram reformuladas. Isso significou, em um primeiro momento, um processo de migração para plataformas digitais, além da proposta de alternativas para os alunos que não possuíssem acesso à internet.

Em um momento inicial as equipes gestoras precisaram se reunir em formato virtual com a equipe técnica de informática de Secretaria Municipal de Educação da área da informática com o objetivo de ser capacitada com o uso das novas tecnologias para as aulas, e em um momento posterior oferecer capacitação ao corpo docente para atender as novas demandas educacionais. Para tratar desse tópico é necessário abordar as novas tecnologias e de que maneira essas estão profundamente incorporadas na rotina escolar. Para abordarmos essa temática de acordo com Moran (2013), é fundamental compreender a importância dos meios de comunicação que:

[...] operam imediatamente com o sensível, o concreto, principalmente a imagem em movimento. Combinam a dimensão espacial com a cinestésica, onde o ritmo toma-se cada vez mais alucinante (como nos videoclipes). Ao mesmo tempo utilizam a linguagem conceitual, falada e escrita, mais formalizada e racional. Imagem, palavra e música integram-se dentro de um contexto comunicacional afetivo, de forte impacto emocional, que facilita e predispõe a aceitar mais facilmente as mensagens. (MORAN, 2013, p. 33-34)

O autor ainda destaca que o papel da linguagem audiovisual, que consegue ir além da capacidade consciente:

A força da linguagem audiovisual está no fato de ela conseguir dizer muito mais do que captamos, de ela chegar simultaneamente por muitos mais caminhos do que conscientemente percebemos e de encontrar dentro de nós uma repercussão em imagens básicas, centrais, simbólicas, arquetípicas, com as quais nos identificamos ou que se relacionam conosco de alguma forma. (MORAN, 2013, p. 34)

Após o momento de capacitação, as esquipes gestoras se reuniram com o corpo docente das unidades escolares para promover a capacitação. A plataforma escolhida foi o Google Classroom, com parceria com uma universidade do município, que ofereceu a parte técnica de cadastro dos alunos e docentes no sistema, bem como a criação de e-mails institucionais para 
esta finalidade ${ }^{1}$. As aulas no formato remoto foram inicialmente elaboradas pelas coordenadoras das unidades escolares de forma coletiva, visando atender os componentes curriculares obrigatórios: Língua Portuguesa e Matemática.

Para atender a todos os alunos foi pensada em uma estratégia que contemplasse uma alternativa: os alunos que alegassem dificuldades ou ausência de acesso à internet, teriam como opção irem até a unidade escolar uma vez por semana retirar as cópias impressas das atividades. Essa alternativa é vista como uma modalidade de Ensino Híbrido cuja concepção apresentamos a seguir:

\begin{abstract}
Híbrido significa misturado, mesclado, blended. A educação sempre foi misturada, híbrida, sempre combinou vários espaços, tempos, atividades, metodologias, públicos. Agora esse processo, com a mobilidade e a conectividade, é muito mais perceptível, amplo e profundo: trata-se de um ecossistema mais aberto e criativo. O ensino também é híbrido, porque não se reduz ao que planejamos institucionalmente, intencionalmente. Aprendemos através de processos organizados, junto com processos abertos, informais. Aprendemos quando estamos com um professor e aprendemos sozinhos, com colegas, com desconhecidos. Aprendemos intencionalmente e aprendemos espontaneamente. (BACICH e MORAN, 2015, p. 45)
\end{abstract}

As atividades foram pensadas em um modelo preestabelecido, oficial com o timbre oficial. Dessa forma, os professores deveriam formular a partir dali para postar na plataforma. De acordo com as orientações iniciais foram vedadas algumas modalidades de exercícios como aqueles que exigissem que os alunos precisassem colorir, ou ligar, caça palavras entre outros, dada a impossibilidade de serem realizadas no formato remoto. Após o primeiro mês de atividades com os componentes curriculares obrigatórios, entraram na plataforma os componentes diversificados do currículo como a Educação Física e a Língua Inglesa.

Para uma melhor organização os professores de inglês foram divididos em grupos de acordo com as turmas atendidas no Ensino Fundamental I. Como atualmente a Língua Inglesa é oferecida apenas a partir do segundo ano, foram criados quatro grupos, que ficaram responsáveis pela elaboração das aulas de cada uma das turmas. Uma vez por semana, essas aulas deveriam ser compartilhadas para que todos os professores pudessem ter acesso e fazer as devidas alterações, sugestões de acordo com a realidade de sua comunidade escolar. A partir dessa dinâmica os subgrupos possuem autonomia para organizar a estruturação das aulas.

Como no início do ensino remoto não houve postagem de aulas de Língua Inglesa, o grupo se organizou em reuniões para reorganizar o Plano Anual de Ensino que havia sido

\footnotetext{
${ }^{1}$ Essa parceria foi sem custos entre a Secretaria Municipal de Educação e a Universidade em questão. Optamos por preservar o nome da instituição.
} 
elaborado em fevereiro, para conseguir definir quais objetos de conhecimento seriam abordados durante os primeiros meses de aula remota ${ }^{1}$.

A proposta a seguir, aconteceu no contexto de uma aula via Google Meet, para a turma do quarto ano do EF-I, na qual a professora de Língua Inglesa estava trabalhando os lugares da cidade. Para cada objeto de conhecimento são pensadas três aulas com o propósito de:

Na primeira aula o objetivo é introduzir os vocábulos novos de forma escrita e com imagens. Na segunda aula o objetivo principal é reforçar os vocabulários que foram apresentados, após essa contextualização, que em condições presenciais geralmente ocorre com a apresentação de flashcards, é possível ampliar com os alunos os vocabulários em diálogos. Essa estratégia foi escolhida, em especial, para os quartos e quintos anos do EF-I, que são os últimos dos anos iniciais, e nos quais os alunos conseguem ter mais autonomia com a linguagem escrita. Assim, essas atividades podem ser utilizadas em Língua Inglesa, embora não seja o foco das aulas. Com o ensino remoto, os professores precisaram lançar mão de recursos que focassem na linguagem escrita, enfatizando, nesse sentido, a importância da participação dos familiares no auxílio do desenvolvimento das atividades.

Em um terceiro momento, a opção é sistematizar os conhecimentos que foram propostos de forma que o objeto de conhecimento seja de fato compreendido. Portanto, nessa terceira aula, as atividades, sempre revisam os vocábulos e expressões estudadas. Segue um exemplo de exercício elaborado, no qual o aluno deve circular a opção correta de acordo com a imagem, assim é necessário mobilizar os conhecimentos adquiridos sobre os vocábulos.

Apesar de ter bem definido essa proposta de três aulas para abordar cada objeto de conhecimento, é evidente que com a ausência das aulas presenciais, as aulas de Língua Inglesa sofreram transformações.

Neste processo de ensino remoto, uma das possibilidades foi a adoção de aulas síncronas como alternativas. É importante delimitar que as atividades de Língua Inglesa foram basicamente elaboradas a partir de fichas com atividades coloridas, e visando ao máximo facilitar a compreensão dos alunos e de seus familiares. No momento de ensino pandêmico, os familiares atuam no processo de ensino aprendizagem, exigindo que o professor adapte suas atividades para que estas sejam acessíveis. No caso da língua estrangeira, este fator deve ser levado em consideração em especial. Por este motivo, alguns professores adotaram o uso de vídeos se configurando como aulas assíncronas, sendo esses materiais de apoio para as

\footnotetext{
1 Não havia, nesse momento, nenhuma perspectiva quanto ao retorno das aulas presenciais, portanto esse planejamento foi feito de forma preliminar.
} 
atividades disponibilizadas semanalmente. Como em algumas unidades escolares, os professores do ensino regular passaram a ministrar aulas síncronas uma vez por semana via Google Meet, com o objetivo principal de corrigir as atividades da semana. Assim, foi oferecida essa alternativa aos professores de inglês, com caráter facultativo.

A justificativa pela oferta de aula síncrona se faz pela necessidade de, em língua estrangeira, ser fundamental a interação entre professor e aluno. Nas atividades propostas, sempre foram sugeridos vídeos como recursos para facilitar a compreensão oral dos alunos. No entanto, essa alternativa não supre de forma adequada as demandas educacionais para esse componente curricular, que tem como foco principal nessa faixa etária a produção oral.

Ao realizar a aula síncrona via Google Meet, a professora usou como recurso para o objeto de conhecimento lugares da cidade, o Google Maps para mostrar para os alunos diferentes lugares na cidade com imagens reais, utilizando-se da realidade aumentada. Foi possível que os alunos solicitassem lugares para serem "visitados" e um deles foi a Estátua da Liberdade em Nova Iorque. Com esta proposta foi possível exercitar a produção oral desses vocábulos.

\title{
3. CONSIDERAÇÕES FINAIS
}

A adoção de aulas síncronas como estratégia ainda é recente e pouco utilizada pelos professores de Língua Inglesa, embora já esteja, lentamente, sendo disseminado no contexto público municipal, pelos professores da sala regular. Alguns obstáculos são importantes, ao fazer a opção por essa modalidade. O acesso é ainda um ponto sensível, e que demanda atenção por parte das políticas públicas que garantam a inclusão digital. É importante destacar que existem diversos benefícios proporcionados pelo uso da internet conforme são explicitados a seguir:

\begin{abstract}
A Internet pode ajudar a desenvolver a intuição, a flexibilidade mental, a adaptação a ritmos diferentes. A intuição, porque as informações vão sendo descobertas por acerto e erro, por conexões "escondidas". As conexões não são lineares, vão "linkando-se" por hipertextos, textos interconectados, mas ocultos, com inúmeras possibilidades diferentes de navegação. Desenvolve a flexibilidade, porque a maior parte das sequências são imprevisíveis, abertas. A mesma pessoa costuma ter dificuldades em refazer a mesma navegação duas vezes. Ajuda na adaptação a ritmos diferentes: a Internet permite a pesquisa individual, em que cada aluno trabalhe no seu próprio ritmo, e a pesquisa em grupo, em que se desenvolve a aprendizagem colaborativa. (MORAN, 2013, P. 53)
\end{abstract}

Foi possível observar que, nas aulas síncronas os alunos conseguem participar via telefone celular, o que se mostrou mais difícil para a utilização da plataforma do Google Classroom, quando o único equipamento disponível para a realização das atividades era o 
aparelho. Como as escolas oferecem as atividades impressas, existe um número expressivo de alunos que acompanham as aulas via plataforma, mas optam por realizar as atividades impressas, devido à dificuldade de leitura no dispositivo móvel.

Para facilitar o acesso, todas as aulas são gravadas e disponibilizadas posteriormente, justamente em caso de problemas de conexão ou de impossibilidade do aluno estar presente durante toda a aula. O contato com os familiares tem sido possível via aplicativo de troca de mensagens que permite o compartilhamento de materiais, atividades e vídeos, conforme a necessidade. Nesse sentido, pode se dizer que:

O professor atua como coordenador, motivador, elo do grupo. [...]O professor utiliza uma parte do material preparado de antemão (planejamento) e enriquece-a com as novas contribuições da pesquisa grupal (construção cooperativa). Assim o papel do aluno não é o de "tarefeiro", o de executar atividades, mas o de co-pesquisador, responsável pela riqueza, pela qualidade e pelo tratamento das informações coletadas. O professor está atento às descobertas, às dúvidas, ao intercâmbio das informações (os alunos pesquisam, escolhem, imprimem), ao tratamento das informações. O professor ajuda, problematiza, incentiva, relaciona. (MORAN, 2013, P. 48)

\section{REFERÊNCIAS:}

BACICH, L.; MORAN, J. Aprender e ensinar com foco na educação híbrida. Revista Pátio, $\mathrm{n}^{\mathrm{o}}$ 25, junho, 2015, p. 45-47. Disponível em: http://www2.eca.usp.br/moran/wpcontent/uploads/2015/07/hibrida.pdf Acesso em: 17 de setembro 2020.

BACICH, L., MORAN, J. (Orgs). Metodologias ativas para uma educação inovadora: uma abordagem teórico-prática. Porto Alegre, Penso, 2018.

MORAN, J. M. et al. Novas tecnologias e mediação pedagógica. Campinas: Papirus, 2013.

ROCHA, C. H. Propostas para o inglês no ensino fundamental público: plurilinguismo , transculturalidade e multiletramento. Tese (doutorado em Linguística Aplicada). Instituto de Estudos da Linguagem. Universidade Estadual de Campinas. Campinas, 2010.

VOLÓCHINOV, V. Marxismo e filosofia da linguagem - problemas fundamentais do método sociológico na ciência da linguagem. Tradução Sheila Grillo e Ekaterina Vólkova Américo. São Paulo: Editora 34, 2017. 